Wilfrid Laurier University

Scholars Commons @ Laurier

Kinesiology and Physical Education Faculty

Publications

Kinesiology and Physical Education

2009

\title{
An Examination of the Challenges Experienced by Canadian Ice- Hockey Players in the National Hockey League
}

\author{
Randy C. Battochio \\ Laurentian University \\ Robert J. Schinke \\ Laurentian University \\ Mark A. Eys \\ Wilfrid Laurier University, meys@wlu.ca \\ Danny L. Battochio \\ St. Francis Xavier University \\ Wayne Halliwell \\ Université de Montréal
}

See next page for additional authors

Follow this and additional works at: https://scholars.wlu.ca/kppe_faculty

\section{Recommended Citation}

Battochio, Randy C.; Schinke, Robert J.; Eys, Mark A.; Battochio, Danny L.; Halliwell, Wayne; and Tenenbaum, Gershon, "An Examination of the Challenges Experienced by Canadian Ice-Hockey Players in the National Hockey League" (2009). Kinesiology and Physical Education Faculty Publications. 25.

https://scholars.wlu.ca/kppe_faculty/25

This Article is brought to you for free and open access by the Kinesiology and Physical Education at Scholars Commons@ @aurier. It has been accepted for inclusion in Kinesiology and Physical Education Faculty Publications by an authorized administrator of Scholars Commons @ Laurier. For more information, please contact scholarscommons@wlu.ca. 


\section{Authors}

Randy C. Battochio, Robert J. Schinke, Mark A. Eys, Danny L. Battochio, Wayne Halliwell, and Gershon Tenenbaum 


\title{
An Examination of the Challenges Experienced by Canadian Ice-Hockey Players in the National Hockey League
}

\author{
Randy C. Battochio, Robert J. Schinke, and Mark A. Eys \\ Laurentian University \\ Danny L. Battochio \\ St. Francis Xavier University \\ Wayne Halliwell \\ University of Montreal \\ Gershon Tenenbaum \\ Florida State University
}

\begin{abstract}
Semistructured interviews were used in this study to learn about the challenges experienced by four groups of National Hockey League (NHL) players $(N=11)$ : prospects $(n=3)$, rookies $(n=3)$, veterans $(n=2)$, and retirees $(n=3)$. The database is comprised of 757 meaning units grouped into 11 contextual challenges. From an additional quantitative analysis, the prospects and rookies emphasized challenges pertaining to scouting demands, training camp, increased athletic demands, team expectations, and earning team trust. The veterans spoke mostly of challenges including scouting demands, athletic demands, and team expectations. Retirees considered mostly challenges pertaining to team expectations, athletic demands, lifestyle, media demands, transactions, cross-cultural encounters, and playoffs. An expert panel ensured that the interview guide, data analysis, and the findings represented the participants' experiences in the NHL. Recommendations for practitioners and researchers working with NHL players are proposed.
\end{abstract}

The National Hockey League (NHL) is regarded as the premier professional hockey league in the world (Perlini \& Halverson, 2006), and it is also a featured professional sport in Canada. The league is comprised of 30 teams located throughout North America and players are recruited from various nations includ-

Randy C. Battochio, Robert J. Schinke, and Mark A. Eys are with the School of Human Kinetics at Laurentian University, Sudbury, Ontario, Canada. Danny Battochio is with St. Francis Xavier University in Antigonish, Nova Scotia, Canada. Wayne Halliwell is a professor in the field of applied sport psychology at the University of Montreal in Montreal, Quebec, Canada. Gershon Tenenbaum is the Benjamin Bloom Professor of Educational Psychology at Florida State University in Tallahassee. 
ing Canada, U.S.A., Sweden, Finland, and Russia (Legends of Hockey, 2009). Despite the popularity of ice-hockey in terms of athletes and fan base, few sport researchers have examined the challenges ice-hockey players experience when trying to seek and maintain a roster spot on an NHL team. Hagy (2002) recognized this trend and suggested that most researchers have only resourced readily available data from public records (e.g., points recorded by a player or team). Further, Hagy indicated that there are many gatekeepers who make it challenging to gain access to NHL players. Barriers to in-depth exploration of contextual factors in professional ice-hockey could be attributed to this limited access to the athletes, an inability to build interest among athletes in sport psychology research, and also extensive commitments associated with training, performance, sponsorship, and media.

Despite the barriers described above, authors have provided a glimpse into the psychological demands of professional level sport, an aspect we refer to as "contextual factors" (e.g., Botterill, 1990, 2004; Hagy, 2002; Halliwell, 1990, 2004; Salmela, Marques, Machado, \& Durand-Bush, 2006; Schinke, Gauthier, Dubuc, \& Crowder, 2007). Côté et al. (1995) interviewed 17 expert high-performance gymnastics coaches for the purpose of identifying and organizing the variables that affect elite coaches into a comprehensible framework. As a result, they unveiled the coaching model (CM) that consists of six components: (a) competition, (b) training, (c) organization, (d) coach's personal characteristics, (e) athlete's personal characteristics, and (f) contextual factors. Among the six components, only contextual factors pertain to the present investigation, albeit in relation to professional athletes. Côté et al. defined contextual factors as those situational variables within a sport context that can influence an athlete's performance but do not include the coaches and athletes themselves. Included in the contextual factors were parents, assistant coaches, subjective officiating, and job conditions. Gilbert and Trudel (2000) were the first sport researchers to use the CM to examine the role of contextual factors in ice hockey, applying a single-case study design with a university ice hockey coach. They indicated that the contextual factors (i.e., parents, assistant coaches, and job conditions) identified by the lone participant matched those uncovered in Côté et al.'s report.

Along a similar line, Salmela et al. (2006) considered the contextual factors associated with professional sport when they interviewed four professional coaches from the Brazilian National Football (North American soccer) team attending the 2006 World Cup. It should be noted that most of the authors/researchers reside in Brazil, where football is regarded as the national sport (see Salmela $\&$ Moraes, 2003). While discussing matters related to membership on the national team, the coaches provided insight into their own experiences as well as those of their athletes. It should be noted that football team coaches and athletes are typically selected as a result of their success as professional athletes. The coaches Salmela et al. interviewed identified two additional challenges related to the context of professional football: cross-cultural encounters and professional lifestyle. The former was particularly relevant when the coaches relocated outside of Brazil and occupied a professional coaching position in another country before being named a national team coach. The coaches mentioned that the athletes on their respective teams possessed different values and customs that needed to be respected. Our authors expected that the aforementioned challenges (e.g., job con- 
ditions, cross-cultural encounters) would extend to the NHL, and that perhaps the challenges encountered by elite coaches might also be experienced by NHL athletes despite the different roles and responsibilities assigned.

It is worthwhile pointing out that, at present, most of what sport psychologists know of the lived experiences of NHL players is based upon anecdotal second hand evidence, authored by practitioners. Botterill $(1990,2004)$ and Halliwell $(1990,2004)$, two sport psychology consultants, commented on their experiences as consultants in the NHL, each on two separate occasions. Botterill (1990) revealed the mental training strategies attempted by NHL players and, pertinent to the present report, the demands (e.g., training camp, development demands, and playoffs) that catalyzed the players' interests in mental training. Recently, Botterill (2004) explained that his priority as a consultant, based upon experiences with the Chicago Blackhawks and New York Rangers, among other teams, is to meet the psychological needs (i.e., installing objectives and developing relevant mental training skills) of each NHL player. Meanwhile, Halliwell (1990) offered another vantage of the mental training strategies used by NHL players when he discussed his experiences as a consultant with NHL teams. He identified the demands encountered by NHL players, including the need to be confident in oneself as well as others, the stress associated with team selection during training camp, and the mental and physical fatigue caused by the NHL lifestyle (i.e., lengthy road trips, numerous games, and intense pressure to perform). More recently, Halliwell (2004) focused on the challenges (e.g., opponents, referees, expectations, and extensive traveling schedule) associated with participating in the Stanley Cup playoffs. Through his work, Halliwell affirmed that the challenges experienced by NHL players are many, leaving sport psychologists with several entry points to inquiry and consultation. Such reports have provided needed information concerning the NHL context; however, they are from the consultants' vantages and do not necessarily resemble those of the intended client.

There are only two studies where sport researchers have conducted qualitative inquiries where the words of NHL players are at the forefront (i.e., Hagy, 2002; Schinke et al., 2007). Recently, Schinke et al. considered the views of rookies and veteran NHL players with different cultural backgrounds. The authors analyzed archived newspaper articles to identify and describe the adaptation process relevant to each developmental group. Within their analysis, the authors uncovered four adaptation challenges as the professional hockey players attempted to adjust to their lives as NHL players: (a) obtaining and maintaining a roster spot, (b) relocation, (c) understanding one's role on the team, and (d) cross-cultural encounters. Despite their contribution, Schinke et al. noted that they employed a second hand data source and that in future attempts, first hand data should be gleaned, enabling researchers to pose systematic questions leading to a greater understanding of NHL players' experiences. Hagy (2002) provided a first hand account interviewing three retired NHL players to learn about their experiences in amateur and professional hockey. The findings included three themes that could be regarded as contextual challenges, since the participants indicated a need to manage these themes: (a) relocating as a result of being promoted, (b) maintaining superior physical conditioning, and (c) preventing demotion. Still, the purpose was to learn about the retired players' experiences in the NHL as opposed to determining whether the player experienced any specific challenges. Also worth 
considering, the views of retired respondents may not hold true with NHL players across levels of experience (i.e., prospects, rookies, and veterans), since their views are captured in retrospect and may have been influenced through faulty memory (Schinke \& da Costa, 2000).

Consequently, a semistructured, open-ended interview was conducted with NHL players categorized into one of four groups: prospects, rookies, veterans, or retired players. Our authors suspected that based on a player's level of experience, there might be differences in terms of the content and frequency of each challenge identified. It should be noted that the present report on contextual challenges is part of a larger inquiry geared toward studying not only the NHL players' challenges, but also their subsequent adaptation strategies first hand.

The purpose of the current study was to identify and describe the challenges experienced by Canadian NHL players at four different career stages through the use of a first-hand data source (i.e., semistructured interview). Furthermore, the authors sought to learn if the challenges experienced differed according to the NHL player's career stage.

\section{Method}

The study's methodology is comprised of six sections: participants, researchers' assumptions, expert panel, question development, analysis protocol, and trustworthiness.

\section{Participants}

The participants comprised 11 current and former NHL players from Canada (3 prospects, 3 rookies, 2 veterans, 3 retired players). Prospects were Canadian junior and college hockey players whose rights were owned by an NHL team, though they had yet to play in the NHL. The rookie group (averaging 56 games played) was comprised of NHL players promoted to the NHL within the 2006-07 or 2007-08 regular seasons. The veterans (averaging 451 games played) consisted of those who began playing in the NHL before the 2006-07 regular season and occupied a roster spot on an NHL team at the time of their interview. The retired players (averaging 452 games played) consisted of those no longer active on an NHL roster, though with at least seven seasons of amassed experience. The retired group provided a global overview of experiences from the beginning of professional careers, onward to retirement.

Participant recruitment was developed through the application of Patton's (2002) purposive convenience sampling method. The goal of Patton's technique is not to seek representation, but to select participants based on their accessibility to the researcher and for their rich information contributions to the subject matter. Participant recruitment was constrained to players available throughout the 2008 NHL off-season and regular season schedule. Immediately following the project's approval from the first author's university's IRB, the participants were enlisted by word of mouth. As a result, the participants of the current study were selected based on their accessibility to the first (former Tier 2 hockey player) and third (former major junior hockey player and invitee to an NHL training camp) authors who had an existing relationship with each participant before the study. 


\section{Researchers' Assumptions}

The first three authors were present during a bracketing interview aimed at explicating the underlying assumptions about the research project (Ahern, 1999). The areas discussed were our personal experiences in the sport of hockey, our link to each of the participants, as well as the anticipated responses to the questions posed through the open-ended, semistructured interview guide. Due to their existing relationship with each of the participants, and the use of an open-ended, semistructured interview guide, the authors suspected that the participants would be more inclined to share the details of their experiences, which could potentially lead to some novel findings. Further, it was posited that the challenges identified by Schinke et al. (2007) might also surface within the current study. The first author kept a reflexive journal outlining each of the topics discussed in the bracketing session (e.g., research question, participant selection, data analysis).

\section{Expert Panel}

An expert panel was assembled to verify (a) the development of the interview guide, (b) the analysis of the data, and (c) the interpretation of the findings. The panel was comprised of a former NHL player with 14 years of experience in the league, a family member (i.e., sibling) of an NHL player who had 6 years of experience in the NHL, and a former teammate of an NHL player of 3 years. Together, these experts provided contextual knowledge from three different vantage points to guard against unfounded views from the researchers (first two authors). An expert coauthor, with over 20 years of experience as a consultant in the NHL, was later recruited to assist with coauthorship.

\section{Question Development}

The semistructured interview guide (see Appendix) was developed in association with the expert panel and was completed in two general stages. First, a tentative list of questions was presented to the expert panel who were asked to provide feedback and enhance contextual relevance. The panel's feedback enhanced the likelihood that the terms included in the interview guide reflected the everyday language of NHL players (see Patton, 2002; Schinke et al., 2007). Within the interview guide, an attempt was made to initially situate the participants in the immediate pre-NHL hockey context and comment on the first time they were contacted by an NHL team. The intent was to learn chronologically about the professional athletes' experiences and follow the emerging challenges as their involvement with NHL teams increased over time. Second, the content of the questions was formulated by using methodological insights gained from previous research projects pertaining to professional sport and contextual challenges. For example, an emphasis was put on Schinke et al.'s (2007) work pertaining to NHL players whereby four challenges were identified. The challenges included the demands associated with being promoted to the NHL, maintaining their roster status, dealing with the relocation process resulting from a trade, and cross-cultural encounters. Participants were probed (see Patton, 2002) to seek an in-depth understanding of their lived experiences. Moreover, the interview guide questions (see Appendix) were modified to ensure that they applied to each group. In the 
first question, for example, prospects were asked about their early experiences (e.g., contact with scouts, training camp), knowing that their careers in the NHL had not commenced. In addition, the temporal nature of the questions was tailored to the participant's level of experience.

\section{Analysis Protocol}

The data were analyzed according to Patton's (2002) guidelines. Each interview was audio recorded and transcribed verbatim by the first author. The text was then segmented into meaning units (MU). An MU is a segment of text that contains a single idea related to a specific topic (Tesch, 1990). Names, teams, and locations were removed to ensure anonymity. The first three authors analyzed the content of each MU and placed each MU into a category of contextual challenges. The categories were then organized into a table where the contextual challenges reflected the chronological experiences of NHL players (e.g., draft demands occurred before attending training camp). Subsequently, the table along with the corresponding MUs for each contextual challenge was presented to the expert panel for a final verification of the data. The purpose was to ensure that the findings were reflective of the NHL players' experiences.

\section{Trustworthiness}

The present investigation adhered to Maxwell's (2002) validity guidelines. To enhance descriptive validity, the first author used an audio recorder throughout each interview and transcribed the content verbatim. For interpretive validity, the first three authors integrated the expert panel's feedback regarding the interview guide and the categorization of the data. Theoretical validity was enhanced when the first three authors worked to achieve a negotiated consensus regarding the categorization of the data. Subsequently, the table containing each contextual challenge as well as the corresponding MUs were presented to the expert panel who considered the data's representation. Finally, a professional consultant with applied knowledge of the challenges NHL players encounter was recruited as a coauthor to provide additional feedback regarding the link between the findings and the NHL players' lived experiences. The finding's generalizability is most relevant to Canadian NHL players.

\section{Results}

The analysis was comprised of 757 total MUs, and the challenges are described in chronological order (Table 1). Table 1 contains information with the number of participants per group commenting on each challenge. The challenges date back to when an NHL team contacted each player for the first time until the present day, or when they officially retired. Themes are comprised of scouting demands, training camp, increased athletic demands, team expectations, earning team trust, demotion, NHL lifestyle, media demands, transactions (e.g., trades), cross cultural encounters, and the NHL playoffs. As can be seen in Table 1, there are also indications that each group experienced all of the challenges, though the prospects provided anticipatory information about NHL challenges (e.g., NHL playoffs) 


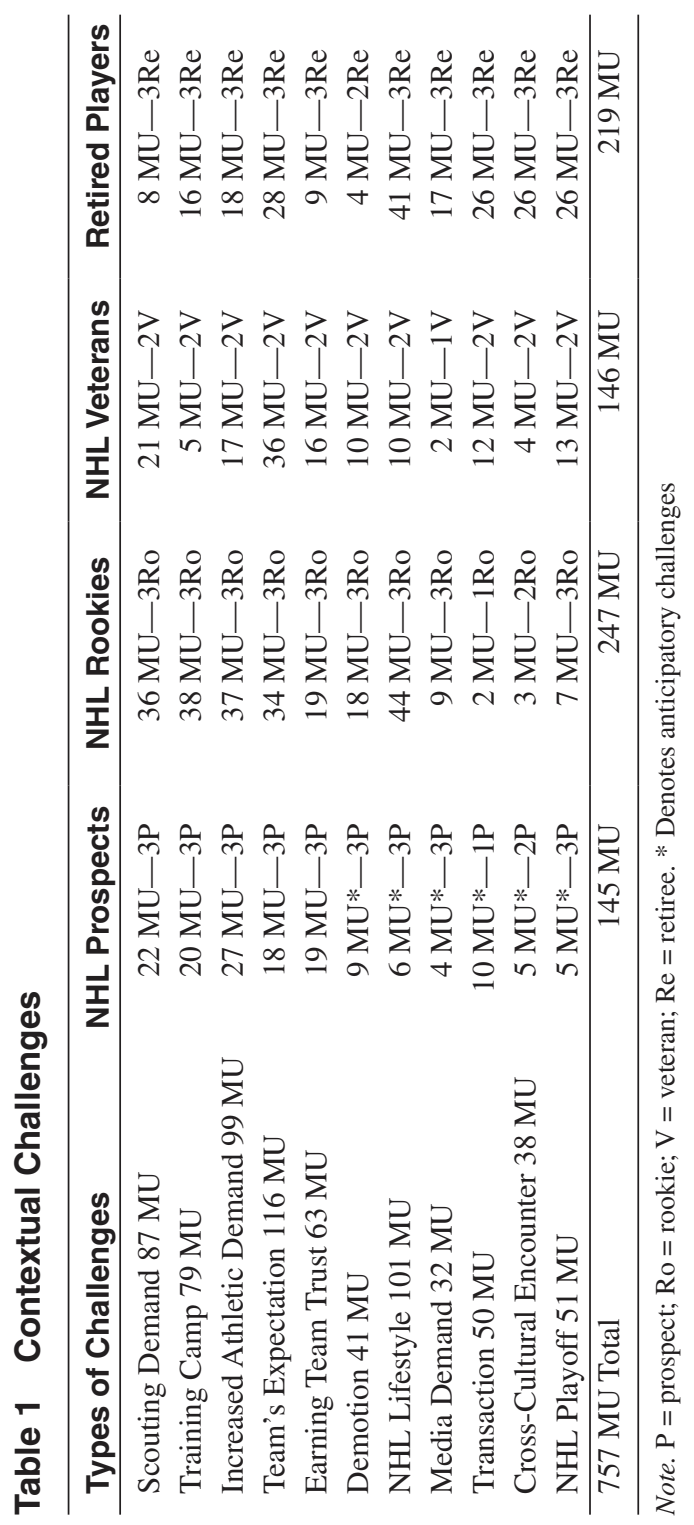


based on vicarious experiences. However, discrepancies (i.e., imbalances in contextual challenges emphasized per group) are considered forthcoming. A nonparametric $\chi^{2}$ procedure was applied to the four categories of players in relation to the MUs resulting in significant differences, $\chi^{2}(d f=30, N=757)=171.2, p<.001$, $L R=185.34, p<.001,(p h i) \varphi=0.48$. Relatively, veterans and rookies had more MUs per player (73.0 and 82.33, respectively) than prospects and retired players (48.3 and 43.0, respectively). The prospects' and rookies' challenges were mainly scouting demands, training camps, increased athletic demands, team expectations, and earning their team's trust (13-19\% each); the veterans' challenges were mainly related to the team's expectations $(24.7 \%)$, but also scouting demands $(14,4 \%)$ and increased athletic demands $(11.6 \%)$; retirees reported retrospectively on their team's expectations (12.8\%), NHL lifestyle $(18.7 \%)$, but also media demands, transactions, cross-cultural encounters, NHL playoffs, and increased athletic demands (7-12\%). Below, abbreviations (i.e., $\mathrm{P}=$ prospect, $\mathrm{Ro}=$ rookie, $\mathrm{V}=$ veteran, and $\mathrm{Re}=$ retiree) linking the MUs to the participant are provided throughout the qualitative descriptions.

\section{Scouting Demands}

Scouts are assigned to a geographical location so they may observe and report the performances of draft eligible players to their respective NHL teams (87 MU). Only retirees failed to indicate this challenge extensively despite all groups admitting that their first contact with NHL teams involved scouts. However, the prospects and rookies shared a different experience compared with their older counterparts resulting from a recent rule change whereby NHL teams were only permitted to meet with draft-eligible players at the NHL Combine for the first time. The NHL Combine is an event attended by NHL teams looking to evaluate prospective players before selecting them in the NHL entry draft. These two groups described their experiences as mentally and physically demanding since they were asked to conduct a variety of interviews and physical tests with a number of NHL teams. The interviews range from an informal conversation with a scout to a formal meeting with a team's management and scouting staff where topics related to the performance on and off the ice is discussed. One rookie explained: "some [interviewers] drill you pretty hard and call you out by asking questions like are you better than this guy? What makes you better?'(Ro3). As for the physical tests, one rookie recalled his experience: "You have every NHL team in the room watching you bike, bench press and use all of these cables. It's very demanding" (Ro2). On the other hand, since the NHL Combine was only introduced 13 years ago, another method was previously employed. The veterans and retired players indicated that before the Combine, scouts were free to hold informal meetings following games. One veteran described this experience supporting the views of both groups: "Teams would do interviews throughout the year to have some background information on us" (V2).

\section{Training Camp}

Upon being drafted to an NHL team, prospects are asked to attend a camp where they are handed a workout and dietary program to follow throughout the summer, 
while rookies and veterans are expected to join the team in the fall for training camp (79 MU). Training camp occurs before the regular season and its purpose varies according to a player's level of experience and current status. Only the prospects and rookies mentioned training camps often. Each prospect remarked similarly to the following: "Camp was definitely an eye-opener because I got to see what the NHL was like" (P3). Rookies had already garnered prior experience at an NHL training camp and were using the opportunity to compete for a roster spot. One rookie recalled his second training camp: "I worked so hard that summer hoping to be in the best shape possible for training camp and it worked. I made the team right out of camp" (Ro2). Another rookie indicated, "Training camp can be a little uncertain-you go and fight for a job" (Ro1). The veterans supported the younger group's assertions and added that despite their increased experience, they were expected to compete at camp to maintain their spot. One veteran stated,

Hockey is now a twelve-month job. We were never the athletes that we are producing nowadays. When I started, most of the players played baseball in the summer, skated a few times and then went straight to camp. These days, it's common to see players return home to work on all aspects of their game. (V1)

The retired players supported the aforementioned statement by noting that although they did not engage in the same intense training as their younger counterparts, they maintained their strength and conditioning during the off-season and used camp "to get back into game shape" (Re1).

\section{Increased Athletic Demands}

The participants acknowledged the increased athletic demands (i.e., mental, physical, technical) associated with playing in the NHL (99 MU) and the challenge was relevant to each group of participants. Pertaining to the mental demands, one prospect said, "I found it to be an eye opener - I was in high school playing major junior hockey, and now I was playing against guys supporting their families" (P3). As the players competed in training camp, exhibition, regular season, and playoff games, they noticed differences between their abilities and those of established players:

I remember competing against 18 and 19 year olds in junior and realizing how strong they were, but now I'm competing against 27 year olds in the NHL thinking "I want to be like them one day." So it's amazing how it goes full circle and it's humbling, you reach the top at one level and then you have to start at the bottom of the next level. (Ro2)

Veterans and retired players recalled their first taste of the NHL and shared the same thoughts as the prospects and rookies regarding athletic demands in the NHL. One veteran and two retired players remembered a technical ability limiting their participation in the NHL. When prompted, each participant responded with a comment that resembled the following citation from a veteran: "My skating probably wasn't up to par to play at the next level at the time" (V1). 


\section{Team Expectations}

While competing in the NHL, the participants communicated with the coaching staff (i.e., head coach, assistants, positional coaches) and feedback was provided regarding their athletic performance (116 MU). Regardless of career stage, each participant revealed that they were given a list of expectations regarding their performance. Prospects were asked to report to their junior hockey teams following camp and commit to workout programs from positional coaches designed to improve specific skill sets. One prospect was told, "Continue to work hard and be more aggressive in games" $(\mathrm{P} 2)$. On the other hand, rookies were given a roster spot immediately after training camp and realized that the NHL team's expectations were quite different from those of junior hockey. One rookie stated, "I had to be ready to play 6 or 7 minutes/game, which is different from playing 20-25 minutes/game in junior" (Ro1). As for the veterans, they constantly discussed their performances with the coaching staff. One veteran remembered having a tactical discussion: "(Coach's name) was very defensive-minded and he wanted me to be good positioning-wise to prevent the other team from getting scoring opportunities" (V2). When the retired players were asked about their exchanges with team members, they remembered speaking mostly about their roles on the team. One retired player recalled a conversation with his head coach where an attempt was made to reunite with his more skilled teammates. He stated, "Listen, I'm a scorer and I want to be reunited with the players that I played well with last year" (Re3).

\section{Earning Team Trust}

Each group of participants understood that once they were drafted to an NHL team, they had to earn a roster spot in part by earning team trust, particularly that of the general manager and head coach, the decision makers (63 MU). Only the prospects and rookies reported extensively about team trust. One prospect anticipated that gaining his team's trust would lead to a roster spot: "In (name of NHL team), they have ways that they want their players to play and if you don't then you're never going to play for the organization" (P3). Another prospect indicated, "I just have to keep working and hopefully they'll take me" (P2). One rookie supported the prospect's statement when he described his journey and said, "I was really excited to be drafted because (name of NHL team) obviously had confidence in me and I didn't want to let them down. Fortunately for me I have lived up to their expectations so far" (Ro2). Another rookie recalled, "(Team) sent me down but soon enough they had some injuries and felt I was ready so they called me up and I ended up sticking with them" (Ro3). To maintain that trust bestowed on them and maintain their roster spot, the veterans and retired players explained that players must raise their expectations and consistently perform at a high level. One veteran player affirmed the point: "In order to keep your spot, you want to play better than, or at least as good as, the other guys and to do that you have to be the best player on the ice" (V1). Furthermore, one retired player suggested that building strong relationships through consistent performance could prolong a player's career: "If you can maintain a respect level with the guys, it can only lengthen your career by leading to other opportunities" (Re2). These opportunities 
also included competing outside of the NHL at international tournaments as one retired respondent suggested when he acknowledged a manager who "opened the doors for me in international competition" (Re3).

\section{Demotion}

Of those who had obtained a roster spot on an NHL team, nearly all of the participants were demoted to a minor league affiliate at some point (41 MU). All groups of players rarely spoke of being demoted. The prospects, having never been demoted, anticipated that they were going to play in the minors for periods of time before their abilities were sufficiently developed to become full-time NHL players. One prospect based this expectation on an observation made about his NHL team: "They've had players go through their program before and they like to take their time in developing them so they are ready by the age of 25" (P2). One rookie confirmed the prospect's observation when he reflected on the reasons behind his own demotion: "I didn't realize how hard I had to push and I was still a little wet behind the ears when it came to playing in the NHL." (Ro2). The three remaining groups indicated that initially demotion left a negative impression. Another rookie explained that "[being demoted] was a reality check" (Ro1). A veteran experienced a unique situation: "One year was very frustrating because I was shuffled up and down 14 times between the NHL and minors" (V1); however, the four groups knew they needed to regain their spot. According to one retired player, demoted players must "continue to learn while striving to be the best player on the ice in the minors to get the call" $(\operatorname{Re} 2)$.

\section{NHL Lifestyle}

Of those who had secured a spot at the NHL level, several discussed the unique lifestyle associated with playing for an NHL team (101 MU). NHL teams do not house their players with a host family to help them settle into their new community and provide the basic amenities. Rather, the players either lived together in an apartment building or within close proximity and were expected to secure their own food and housing. The prospects anticipated that they would be forced to live on their own, and one prospect supported the group's expectation by recalling a former junior teammate in the NHL who "lived on his own in an apartment but had others living in the same building and across the street" (P1). The rookies, veterans, and retired players recalled experiences that were remarkably similar. One rookie summed it up: "There are some things that you are going to have to come across when you're living alone like not having cooked meals or laundry ready when you come home" (Ro2). Of note, the rookies and retired players mentioned this challenge more than the other challenges, but not the prospect and the veteran players. The rookies provided more information since they compared their recent experiences in the NHL with other leagues (i.e., junior hockey and minor leagues). According to one rookie, "Playing in the NHL is different than the American Hockey League. In the NHL, we take chartered flights everywhere" (Ro3). Meanwhile, the veterans acknowledged the lifestyle's uniqueness and the extensive travel schedule since each team plays 82 games in the regular season, with 41 played away from home; however, one veteran indicated that there are 
ways to manage the schedule: "Typically, we eat out at restaurants a lot because it's easier" (V2). As for the retirees' large number of MUs, they recognized the differences between their current lifestyle as retired players and their former lifestyle as NHL players. One retiree clarified that eating in restaurants was common when in the NHL: "When on the road, we'd eat out at restaurants and at home, you don't buy anything because you won't be in town long" (Re1). Another retiree explained, "When you're playing in the NHL, you can afford to eat out" $(\operatorname{Re} 2)$.

\section{Media Demands}

Members of the media consistently followed the events, and were aware of the expectations surrounding each player's performance (32 MU). When a player surpassed or failed to meet these expectations, the media searched for root causes. Only the retirees provided a substantial amount of MUs regarding the challenge. Prospects noted that they were aware of the media demands in the NHL, and believed that since they were among the higher profile players on their respective junior teams, they had an a priori understanding of the media's role; however, the rookies, veterans, and retirees noted that the media attention in the NHL differs from junior hockey. As one rookie reflected, "It was only a taste of what to expect at the next level" (Ro1). Even among the 30 teams in the NHL, some teams garnered more attention from the media than others. A veteran stated, "Where I play is not as bad as (name of city)" (V2). On the other hand, one retired participant offered a glimpse of his experiences playing for a popular NHL team: "(Name of city) was a fishbowl. We had 25 people flying with us to every game. When you made a mistake they were after you" (Re3). Meanwhile, another retired player considered the media demands of a more celebrated player: "(Name) had a list of commitments that included a guest appearance on (show) and then an interview for (name of magazine). He actually had a guy read him his list of things to do each day-it was long" $(\operatorname{Re} 2)$.

\section{Transaction}

A transaction occurs when one's playing rights are transferred from one NHL team to another through trade or free-agency (50 MU). Mainly the retirees reported this challenge with many MUs including comments (forthcoming) about both trades and free-agency from their own experiences while the remaining groups only offered information regarding transactions if they were once traded or a freeagent. In the present report, only three participants experienced a trade. One prospect recalled being unexpectedly traded in junior hockey and anticipated that it would be equally difficult in the NHL: "One thing about a trade is that you have to leave fast. You have to pack that night and go the next morning" (P1). A rookie experienced a trade as well and admitted, "When I got the call, I was shocked" (Ro3). These words were supported by a retiree who was once surprised by a sudden trade:

I got a call at 6:30 p.m., and I was told by the general manager that he had made a trade and that I was involved. I was headed to (name of city) and that I needed to be out of the house in an hour and half to play in a game that was being played that night. $(\operatorname{Re} 3)$ 
As for free-agency, only the veterans and retired players could offer a first hand account. The participants explained that their contract with their previous team had expired and they were free to sign with another team. One veteran shared his experiences as a free-agent:

I was eligible for arbitration and (NHL team) felt that I was going to win and the number would have been more than they thought I was worth. So they let me go at the deadline, and then tried to resign me but it was time to move on. (V1)

A retiree stated, "Being a free-agent gives you a chance to chose where you want to go" (Re1). Another retiree added, "I went to a team where I fought against one player a bunch of times and we had to all of a sudden be teammates" $(\operatorname{Re} 2)$.

\section{Cross-Cultural Encounters}

All four groups of participants reported that the NHL is a multicultural context (38 MU). However, the retirees provided more information regarding these encounters while the remaining groups simply acknowledged that cross-cultural encounters exist. In addition, it should be noted that most of the participants in the present report share the same cultural background as the majority of NHL players, with one notable discrepancy. A prospect indicated that he experienced some difficulties learning a new language because "[he] came from a French family and had to learn to speak English" (P2). As for the multicultural context of the NHL, the rookies, veterans and retired participants played alongside and against players from different nationalities. The rookies and veterans shared a similar impression of their European teammates. A rookie stated, "They were just like us. They wanted to make a living in the NHL" (V2). This impression was supported by a retired player who also considered two nuances: "I noticed the different things that motivate them. Some of them had a tough upbringing and wanted the opportunities the NHL had to offer. They also led different lives off the ice and ate different foods" (Re3). Another retiree added, "Some have different things motivating them but most of them just want to win or be one of the best players in the NHL" $(\operatorname{Re} 2)$.

\section{NHL Playoffs}

The playoffs are a competition among the teams finishing in at least 8th place in their conference (51 MU). Though some rookies have participated in NHL playoff games, the veterans and retirees considered this challenge frequently. Prospects anticipated that playoffs would be very emotional since losing teams are eliminated while winning teams advance and have a better chance of winning the Stanley Cup trophy. Based on their limited NHL playoff experience, the rookies supported the prospects' prediction and one rookie stated, "The post-season is definitely more intense than the regular season" (Ro3). A veteran player elaborated on the rookie's view based on his increased experience: "In the playoffs, you take one NHL game and you times that by ten. Every play, every shift, every hit, every shot, every pass means something" (V1). When teams win playoff games, it leads to winning a playoff series and eliminating one more team from the compe- 
tition. However, a prolonged playoff run can take a mental and physical toll as another veteran admitted, "I was really worn down when it was over. I had the playoff body, I lost some weight and I was tired" (V2). Regardless, winning playoff games were considered the most rewarding experience an NHL team could have. A retiree stated, "Winning playoff games is a lot of fun and it's neat to see how much a team will bond despite the cast of characters" $(\operatorname{Re} 2)$. Another retiree recalled his playoff experience: "We won the first round and then we took a game from (team) which was great because nobody expected us to beat the defending champs" (Re1).

\section{Discussion}

The present study outlines the contextual challenges associated with being an NHL player, based upon the views of participants at four different career stages. From the present work there appear to be consistencies when the contextual challenges encountered by elite level coaches and NHL athletes are considered. For example, the findings support the overarching theme of contextual factors identified in Côté et al.'s (1995) coaching model (CM) despite the respondent group consisting of professional athletes rather than elite amateur coaches. Côté et al.'s theme of job conditions can be considered a general category similar to the working conditions NHL players are exposed to throughout their careers. Within the present work however, the authors sought to delineate working conditions (i.e., challenges) that reflect the direct views of professional athletes from one sport. For example, NHL players being demoted and playing for a minor league affiliate team, obtaining a roster spot and leading an NHL lifestyle, as well as participating in the NHL playoffs were challenges that resonated among the participants. These nuances within contextual challenges of NHL players, beyond the overarching theme, seemed to match with the particulars identified in professional football by Salmela et al.'s (2006) Brazilian National Team coaches. Though professional athletes and coaches have different responsibilities within an organization, they are still exposed to some similar challenges within professional sport such as the aforementioned job conditions. According to Salmela et al. (2006), professional football coaches recognized the increased athletic ability needed for their competition level, resembling the increased athletic demands posed within the NHL. In addition, the themes of cross-cultural encounters and the lifestyle of professional football paralleled the cross-cultural encounters and lifestyle demands encountered in the NHL. The theme of cross-cultural encounters depicts the multiculturalism (e.g., team members are recruited from different nationalities) of professional sport while through the theme of lifestyle one can recognize the extensive traveling that occurs in professional sport.

Though the findings within the current study delineate various contextual challenges in the NHL, it is not the first manuscript where challenges were identified in professional ice-hockey. Botterill (1990, 2004) and Halliwell (1990, 2004) authored their experiences as NHL consultants, identifying demands placed on the athletes with whom they worked. The authors' views resembled the contextual challenges described first hand within the current study. In Botterill's (1990) earlier work, he explained that players resourced him in training camp, the minor 
leagues, and during playoffs. Such challenges were presented in the current investigation as contextual challenges entitled: training camp, demotion, and NHL playoffs. More recently Botterill (2004) focused on ensuring that the NHL players knew their roles and were committed to their teams' goals, which resembles the challenge of learning the team's expectations in the current study. Halliwell (1990) identified demands such as building confidence in oneself as well as others, attending training camp, and withstanding the demands posed through the NHL lifestyle. Halliwell's challenges are likened to the contextual challenges herein of earning the trust of team members, training camp, and the NHL lifestyle. Finally, Halliwell's (2004) more recently focused on the demands of the NHL playoffs, which resembles the contextual challenge-NHL playoffs herein. As such, the challenges delineated by the aforementioned consultants were supported. However, it is worth noting that the findings in the present report extend Botterill and Halliwell's work since a systematic approach (i.e., semistructured interview) was employed to indentify and describe 11 contextual challenges encountered by NHL players during different career stages. When the four participant groups were considered in our work there is indication that there are several contextual challenges that NHL athletes encounter. However, the salience of the contextual challenges can vary dependent on where the athlete is in his professional career.

The findings within the current study also parallel those uncovered in Hagy (2002) and Schinke et al.'s (2007) qualitative inquiries. Hagy (2002) identified three themes we regard as contextual challenges: (a) relocating as a result of being promoted, (b) maintaining physical conditioning, and (c) preventing demotion. Schinke et al. (2007) uncovered four adaptation challenges: (a) obtaining and maintaining a roster spot, (b) relocation, (c) understanding one's role, and (d) cross-cultural encounters. Hagy and Schinke and colleagues previewed the challenges professional hockey players encountered in the NHL, provisionally based on a pilot study from the former author and archival data from the latter authors. The challenges identified by the authors were supported when participants from the current study discussed transactions, meeting athletic demands, demotion, earning trust of decision makers, learning the team's expectations, and cross-cultural encounters. Further, two additional challenges were identified: scouting and media demands. From the earlier qualitative research and also the current study, it becomes clearer what exactly is challenging about each theme. For example, being promoted to an NHL roster spot is the result of gaining the trust of the general manager and head coach which can be achieved after a player manages scouting demands, succeeds in training camp, develops his abilities, and meets the team's expectations.

Finally, the present report included a quantitative analysis of the frequency players in different career stages experience challenges in the NHL. This is beyond an in-depth qualitative depiction of each contextual challenge from the first hand views of NHL players. Generally, there is indication that prospects and rookies discussed matters related to seeking out a roster spot starting from scouting demands and finishing with earning team trust. Meanwhile, veterans were more concerned with meeting the team's expectations because doing so ensured that they maintained their roster spot. As for the retirees, the group offered information related to the challenges outside of competition such as media demands, transactions, and cross-cultural encounters while recollecting less concern for 
performance-related challenges that garner roster spots. More precisely, prospects and rookies believed training camp was important since it provided an opportunity to gain a roster spot while the veterans and retirees were already assured a spot. As for athletic demands and team expectations, all groups indicated that overcoming these challenges were imperative to obtaining a roster spot. Earning team trust was mainly discussed by prospects and rookies because they were focused on earning credibility while veterans and retirees noted that teams knew what to expect from them. All groups of players rarely spoke of demotion, either because such experiences were regarded as extremely negative, or because the athletes were focused on seeking NHL status. Of note, rookies provided the most information about demotions which is perhaps an indication of the challenge's relevance to the group compared with the remaining groups who were either ineligible or had not experienced a demotion in a long time. Further, the rookies and retirees spoke often about the NHL lifestyle, which could be the result of having noticed differences in their lifestyle as NHL players compared with when they were elite junior or minor league players, or when they transitioned to retirement. With regards to media demands, transactions, and cross-cultural encounters, only the retirees provided an intensive amount of information which reveals the group's tendency to reflect more globally about the challenges outside of competition such as the media's role in promoting the NHL and the influence of multiculturalism. Lastly, though some rookies did participate in the NHL playoffs, veterans and retirees provided the most information about the playoffs which is likely a result of having more cumulative experience.

\section{Implications}

The present study provides sport researchers and practitioners with a preliminary understanding of the contextual challenges faced by professional ice-hockey players in the NHL. Indeed, there are two additional implications worth considering. First, the sport psychology literature rarely discusses the first hand experiences of professional athletes. This could be the result of several factors, including the lack of access to this hard to reach population (see Hagy, 2002), the fact that some sport psychologists are focused on professional consultation as opposed to academic publications, and the reality that many professional organizations prevent staff members, including sport psychologists, from discussing matters (especially psychological services) related to the organization. In the current study, such barriers were minimized when an author with NHL exposure was included in the research team to facilitate the recruitment of participants. It is proposed that future researchers might employ a similar strategy to successfully recruit professional athletes. Second, the findings include the identification and description of the challenges associated with obtaining and maintaining a roster spot on an NHL team. Consideration of the aforementioned challenges may assist aspiring or current NHL players understand the contextual challenges at each stage of the career process. The findings of this study may also assist elite coaches and sport practitioners facilitating the adaptation process of professional ice-hockey players seeking to obtain or maintain a roster spot. These findings may be equally relevant to sport psychologists by helping them become more aware of the contextual demands of one professional sport. For example, information regarding the life- 
style of an NHL player or the demands of the NHL playoffs could effectively be included into an educational program designed to prepare aspiring NHL athletes and NHL rookies.

\section{Limitations}

There are a number of important limitations to consider within the current study. First, only 11 NHL players/prospects were recruited to provide information about the four career stages. Future researchers would glean stronger and more generalizable information about the challenges experienced during each stage by recruiting more participants. Second, each participant voluntarily participated in the current study, and volunteer populations may be very different than those who chose not to volunteer. Third, it is possible that the preexisting relationships between the authors and the participants may have generated findings that are socially desirable. Fourth, the participants were asked to provide retrospective insight from their NHL experiences. For example, veterans and retired NHL players recalled their experiences as rookies and their responses could not have contained every aspect of their experiences. Fifth, the participants were recruited based on their availability to the researchers who conducted the current investigation from one region in Canada. Consequently, the participants' responses may not reflect those of other Canadian NHL players from large urban areas, nor might they represent the expressions of non-Canadian NHL players. It should be reiterated that the main objective of the present report was to gain an understanding of the lived experiences of NHL players as opposed to seeking out equal representation within the participants and the demographics of the NHL. Sixth, Table 1 indicates contextual challenges that have been identified despite not being supported by all participants in the group (e.g., only 2 retired players experienced demotion rather than 3). These findings can be attributed to the limit of conducting one interview and not having the opportunity to follow up with a second interview due to inaccessibility. Lastly, the participant group consisted of professional male athletes in the sport of ice-hockey, so the findings are not applicable to other populations participating in various professional sport disciplines.

\section{References}

Ahern, K.J. (1999). Ten tips for reflexive bracketing. Qualitative Health Research, 9, 407411.

Botterill, C. (1990). Sport psychology and professional hockey. The Sport Psychologist, 4, 358-368.

Botterill, C. (2004). The psychology of professional hockey. Available at: http://www.athleticinsight.com/Vol6Iss2/ProfessionalHockey.htm. Retrieved January 15th, 2009

Côté, J., Salmela, J., Trudel, P., Baria, A., \& Russell, S. (1995). The coaching model: A grounded assessment of expert gymnastic coaches' knowledge. Journal of Sport \& Exercise Psychology, 17, 1-17.

Gilbert, W.D., \& Trudel, P. (2000). Validation of the coaching model (CM) in a team sport context. International Sports Journal, 4, 120-128.

Hagy, J.F. (2002). Experiential antecedents to reaching the pinnacle of ice-hockey: A qualitative analysis. Dissertation Abstracts International: Section B: the Sciences and Engineering, 62(9-B), 42-59. 
Halliwell, W. (1990). Providing sport psychology consulting services in professional hockey. The Sport Psychologist, 4, 369-377.

Halliwell, W. (2004). Preparing professional hockey players for playoff performance. Available at: http://www.athleticinsight.com/Vol6Iss2/ProfessionalHockeyPlayoffPerformance.htm. Retrieved December 10th, 2008.

Legends of Hockey. (2009). Available at: http://www.legendsofhockey.net/html/ind02facts. htm. Retrieved January 15th, 2009.

Maxwell, J. (2002). Understanding and validity in qualitative research. In M.A. Huberman \& M.B. Miles (Eds.), The qualitative researcher's companion (pp. 37-63). Thousand Oaks, CA: Sage Publications.

Patton, M.Q. (2002). Qualitative research and evaluation methods (3rd ed.). Thousand Oakes, CA: Sage Publications.

Perlini, A.H., \& Halverson, T.R. (2006). Emotional intelligence in the National Hockey League. Canadian Journal of Behavioural Science, 38, 109-119.

Salmela, J.H., Marques, M., Machado, R., \& Durand-Bush, N. (2006). Perceptions of Brazilian football coaching staff in preparation for the World Cup. International Journal of Sport Psychology, 37, 139-156.

Salmela, J.H., \& Moraes, L.C. (2003). Development of expertise: The role of coaching, families, and cultural context. In J.L. Starkes \& K.A. Ericsson (Eds.), Expert performance in sport: Advances in research on sport expertise (pp. 275-294). Champaign, IL: Human Kinetics.

Schinke, R.J., \& da Costa, J. (2000). Qualitative research in sport psychology. Avante, 6, $38-45$.

Schinke, R.J., Gauthier, A.P., Dubuc, N.G., \& Crowder, T. (2007). Understanding athlete adaptation in the National Hockey League through an archival data source. The Sport Psychologist, 21, 277-287.

Tesch, R. (1990). Qualitative analysis types and software. New York: Falmer.

\section{Appendix}

\section{Open-Ended Semistructured Interview Guide: Sample}

\section{Section 1: Introduction}

1. Explanation of the study and its purpose.

2. Starting of audio recorder.

3. Verbal consent obtained from the participant.

\section{Section 2: Adaptation Process of a Rookie National Hockey League Player}

Q01 Before talking about your career in the NHL, how about you give me an idea of your experiences starting from major junior hockey until you had been first contacted by an NHL team.

Q02 What was discussed when you had begun talking to an NHL team? 
- Probe [example]

o You had mentioned that the general manager wanted you to work on a few things, what did he have in mind?

Q03 Thinking back to your first couple of seasons in the NHL, what was it that had allowed you to successfully obtain and maintain a roster spot on an NHL team?

- Probe

o Were there other challenges [i.e., relocation or playoff hockey] that you can think about when you were a rookie? If so, how did you choose to respond?

\section{Section 3: Adaptation Process of an Experienced National Hockey League Player (Participants categorized in the rookie group will go immediately to Section 4).}

Q04 As you had gained some experience in the NHL, what had allowed you to not only retain a roster spot but also take on more responsibilities on your team?

- Probe them?

o In your case, what were these responsibilities and how did you learn about

\section{Section 4: Debriefing}

Q05 From what we have discussed just now, what reflections do you have regarding the topic of adaptation and your experiences in the NHL?

Q06 Are there any other questions or topics that I should have asked about, but didn't regarding your experience in the NHL or the topic of adaptation? 